Research Article

\title{
Development of Nanodrug for Treatment of Breast Cancer Using Mallotus Tetracoccus Leaves- Standardisation, Synthesis and Characterisation
}

\author{
Ramalakshmi Subbiah $^{1,2}$, Krishnaswamy Muthuchelian ${ }^{1}$ \\ ${ }^{1}$ Department of Bioenergy, School of Energy, Environment and Natural Resources, Madurai Kamaraj University, Madurai - 625021 , \\ India. \\ ${ }^{2}$ Department of Agricultural Microbiology, Tamilnadu Agricultural University, Coimbatore-641003. \\ Corresponding author. Telephone: +91 452 2458020. E-mail: drchelian1960@yahoo.co.in
}

Received: May 13, 2016; Accepted: Jun. 15, 2016; Published: Jun. 20, 2016.

Citation: Ramalakshmi Subbiah, Krishnaswamy Muthuchelian, Development of Nanodrug for Treatment of Breast Cancer Using Mallotus Tetracoccus Leaves - Standardisation, Synthesis and Characterisation. Nano Biomed. Eng., 2016, 8(2): 82-90.

DOI: $10.5101 /$ nbe.v8i2.p82-90.

\begin{abstract}
In this study, an ecofriendly, green method for synthesis of silver nanoparticles (AgNP) has been developed using Mallotus tetracoccus (MT) leaves as a reducing agent. The formation of AgNPs was standardised at $\mathrm{pH} 7$ and $60{ }^{\circ} \mathrm{C}$. UV-visible spectroscopy showed the high peak of absorption band at $420 \mathrm{~nm}$. By atomic force microscopic (AFM) and scanning electron microscopic (SEM) observations, the size of the silver nanoparticles was found to be in the range of 46 to $100 \mathrm{~nm}$, with an average size of $73 \mathrm{~nm}$. The energy dispersive x-ray spectroscopic (EDX ) profile of silver nanoparticles showed typical optical absorption peak approximately at $3 \mathrm{keV}$. FTIR spectroscopic study revealed that hydroxyl groups of phenols and carboxylic acids were involved in the formation of AgNPs. Through MTT assay, the cytotoxicity results showed that AgNPs were highly effective on human ductal breast carcinoma cell lines (T47D) (76.8 to 84.9\%). Thus, the MT-synthesized NPs are said to possess significant anticancer activity on cancer cells and very less toxicity on normal cells, which suggests its further applications in medicine.
\end{abstract}

Keywords: Nanodrug; Mallotus tetracoccus; Green synthesis; Silver nanoparticles; Anticancer activity

\section{Introduction}

Mallotus tetracoccus (Roxb.) Kurz. of family Euphorbiaceae, found in Western Ghats of India. The common names include Thavatta, Vatta, Vatta kumbil, Vetta kumbil (malayalam), Uppale mara (kannada) and "vatta kanni" in Tamil. Several species of the genus Mallotus are a rich source of biologically active compounds such as phloroglucinols, tannins, terpenoids, coumarins, benzopyrans and chalcones $[1,2]$. The reported bioactivities of the extracts or the individual chemical constituents isolated from this genus include antipyretic [3], anti-inflammatory, hepatoprotective [4], antioxidant and radical scavenging activities [5].

The GC-MS analysis of Mallotus tetracoccus ethanolic leaf extract have revealed the presence of Bis (2-ethyl hexyl) phthalate (46.78\%), 3-methyl-2-(2- 
oxypropyl) furan (13.31\%), E-8-methyl-9-tetradecen1-ol acetate $(6.63 \%)$, Octadecanoic acid, 2-oxo (4.46 $\%)$ and Longiborneol (2.39\%) [6]. The bark of $M$. tetracoccus have been reported for high antioxidant and antibacterial activity [7]. Also, the bark extract studied for GC-MS showed presences of thiocyanic acid, furfural and 4H- Pyran-4 -one, 2, 3- Dihydro-3, 5- dihydroxy-6- methyl compounds. The bark extract showed significant cytotoxicity and phytotoxicity on radish seeds [8].

Thus, the leaves of MT have been used for synthesis of silver nanoparticles. Since time immemorial, silve has been used for curing various diseases due to its antibacterial properties. Recently, silver is gaining a role in development of nanoparticles for cancer therapy, biosensors, dressings, devices, formulations etc. [9]. The objective of this study was to characterize and study the anticancer potential of silver nanoparticles synthesized from MT leaf extract.

\section{Materials and Methods}

\section{Plant material and preparation of the extract}

Fresh and intermediate leaves of Mallotus tetracoccus (Roxb.) Kurz was collected from Agasthiar Malai Biosphere Forest, Western Ghats, collected plant materials were identified and authenticated by the Director, Centre for Biodiversity and Forest Studies (CBFS), MKU, and voucher specimens were deposited in the herbarium of CBFS of university (No. AM-02). The dry leaves was cut into small pieces and powdered finely. About $5 \mathrm{~g}$ of the leaf powder was boiled for 10 min in $100 \mathrm{ml}$ sterile double distilled water and further filtered through Whatman No. 1 filter paper and used for the present study.

\section{Synthesis of silver nanoparticles}

Silver nitrate $\left(\mathrm{AgNO}_{3}\right)$ procured from SigmaAldrich (Bangalore, India) was used. For the synthesis of silver nanoparticles, $\mathrm{AgNO}_{3}(2 \mathrm{mM})$ and aqueous plant extract $(10 \mathrm{mg} / \mathrm{ml})$ were mixed in different ratios. Briefly, $1 \mathrm{ml}$ of plant extract was mixed with $9 \mathrm{ml}$ of $\mathrm{AgNO}_{3}$ (1:9 ratio). The subsequent mixtures were prepared by increasing plant extract and decreasing $\mathrm{AgNO}_{3}$ volumes by $1 \mathrm{ml}$, until the final ratio of 9:1 was attained. Furthermore, appropriate concentrations of $\mathrm{AgNO}_{3}$ and plant extracts vice versa from 1 to 9 ratio mixed in a series of reactions for optimization of synthesis of silver nanoparticles, incubated overnight at room temperature in dark. The resultant yellowish brown solution indicated the formation of silver nanoparticles.

The above mentioned procedure was repeated for optimization of temperature and $\mathrm{pH}$. The $\mathrm{pH}$ was studied in the range of 5, 6, 7, 8 and 9 by using 0.1 $\mathrm{N} \mathrm{HCl}$ and $0.1 \mathrm{~N} \mathrm{NaOH}$ respectively. The reaction temperature was studied at $30^{\circ} \mathrm{C}$ to $70{ }^{\circ} \mathrm{C}$.

\section{Purification of silver nanoparticles}

The broth containing nanoparticles was centrifuged at $15000 \mathrm{rpm}$ for $15 \mathrm{~min}$ to obtain the pellet which was redispersed in sterile deionized water to get rid of any biological molecules. The process of centrifugation and redispersion in sterile deionized distilled water was repeated thrice to obtain better separation of entities from the metal nanoparticles. The purified pellet was then freeze dried using Lyophillizer (Micro Modulyo 230 freeze dryer, Thermo Electron Corporation, India).

\section{UV-visible spectral analysis}

The colour change was observed in the silver nitrate solution incubated with aqueous plant extract. The bioreduction of $\mathrm{Ag}$ nanoparticles was monitored by periodic sampling of aliquots $(0.2 \mathrm{~mL})$ of aqueous component and measuring the absorbance and spectrum of the solution in UV spectrophotometer (Shimadzu, UV 2500, Japan), at a resolution of $1 \mathrm{~nm}$ between 300 and $600 \mathrm{~nm}$. The nanoparticle solution was diluted 20 times with deionized water to avoid errors due to high optical density of the solution.

\section{Atomic force microscopy}

A thin film of the sample was prepared on a cover slip by droping $0.1 \mathrm{ml}$ of the sample on the slide, and allowed to dry for 30 minutes. The slide was then scanned with AFM (APE Research-model no: A100SGS). The AFM characterization was carried out in ambient temperature in non contact mode using silicon nitrate tips with varying resonance frequencies. These tips have spring constants of approximately 0.15 $\mathrm{Nm}-1$ and are conical in shape with a cone angle of $20^{\circ}$ and an effective radius of curvature at the tip of $10 \mathrm{~nm}$.

\section{Fourier transform infra-red (FTIR) spectroscopy}

For FTIR measurements, bioreduced silver NP dried powder was analyzed using FTIR. The samples were 
dried, grounded with $\mathrm{KBr}$ pellets and analyzed in a SHIZAMAZU model no 8400 S spectrum instrument. A disk of $50 \mathrm{mg}$ of $\mathrm{KBr}$ was prepared with a mixture of $2 \%$ finely dried sample, and was then examined under IR-spectrometer. Infrared spectrum was recorded in the region of 500 to $4500 \mathrm{~cm}^{-1}$.

\section{Scanning electron microscopy (SEM) and energy dispersive X-ray analysis (EDX)}

The lyophilized silver NPs were mounted on the copper stubs and the images were studied using scanning electron microscope (SEM). EDX analysis was done with (JEOL model-L6390) secondary electron detectors at an operating voltage of $30 \mathrm{kV}$.

\section{Cytotoxic activity}

\section{Cell culture}

Human ductal breast carcinoma cells (T47D) was obtained from the National Centre for Cell Science (NCCS), Pune, and maintained in Roswell Park Memorial Institute (RPMI) medium containing 10\% fetal bovine serum (FBS). For evaluation of the cytotoxicity, cell was seeded on a 96 well plate with a density of $1 \times 104$ cells $/ \mathrm{cm}^{2}$. Normal cells of L929 (human fibroblast cell line) was maintained in MEM (minimum essential medium) containing 10\% fetal bovine serum (FBS) provided by Promo Cell Germany.

\section{Assessment of cytotoxicity}

Cytotoxicity of NTR was evaluated by using the MTT [3-(4,5-dimethylthiazole-2-yl)-2,5diphenyltetrazolium] assay. This colorimetric test is based on the selective ability of viable cells to reduce the tetrazolium component of MTT into purple coloured formazan crystals. Stock solution of the samples were freshly prepared $(1 \mathrm{mg} / 1 \mathrm{~mL})$ and diluted with cell culture medium to the desired concentrations (20,50 and $100 \mathrm{mg})$. The compound with different concentration was added and incubated with phosphate buffer saline (PBS) resuspended cells, after attaining $90 \%$ confluency. Cells in media devoid of compound acted as the negative control and wells treated with Triton X-100 as the positive control for a period of $48 \mathrm{hrs} .5 \mathrm{mg}$ of MTT (Sigma) was dissolved in $1 \mathrm{ml}$ of PBS and filter sterilized. $10 \mathrm{ml}$ of MTT solution was further diluted to $100 \mathrm{ml}$ with $90 \mathrm{ml}$ of serum and phenol red free medium. $100 \mathrm{ml}$ of the solubilisation solution (10\% Triton X-100, $0.1 \mathrm{~N} \mathrm{HCl}$ and isopropanol) was added to each well and incubated at room temperature for $1 \mathrm{hr}$ to dissolve the formazan crystals. The absorbance of the solution was measured at a wavelength of $570 \mathrm{~nm}$ using a Beckmann Coulter Elisa plate reader (BioTek Power Wave XS). Triplicate samples were analyzed for each experiment.

\section{Statistical analysis}

The values are presented as mean $\pm \mathrm{SD}$ (standard deviation) of triplicate measurements.

\section{Results and Discussion Biosynthesis of silver nanoparticles}

In this study, the AgNPs were rapidly formed soon after the addition of clear silver nitrate solution to the aqueous extract of MT leaves, which was indicated by the light yellowish color turning to the dark brown color after 24 hrs (Fig. 1). The UV-Vis spectroscopy examined the size and shape of nanoparticles at the range of 300-600 $\mathrm{nm}$. Among the various combinations (Fig. 2(a), 2(b)) used for optimization of silver nanoparticle formation, the mixture of $6: 4$ (S6) of silver nitrate and plant extract gave the optimized absorption spectrum at $420 \mathrm{~nm}$, which is
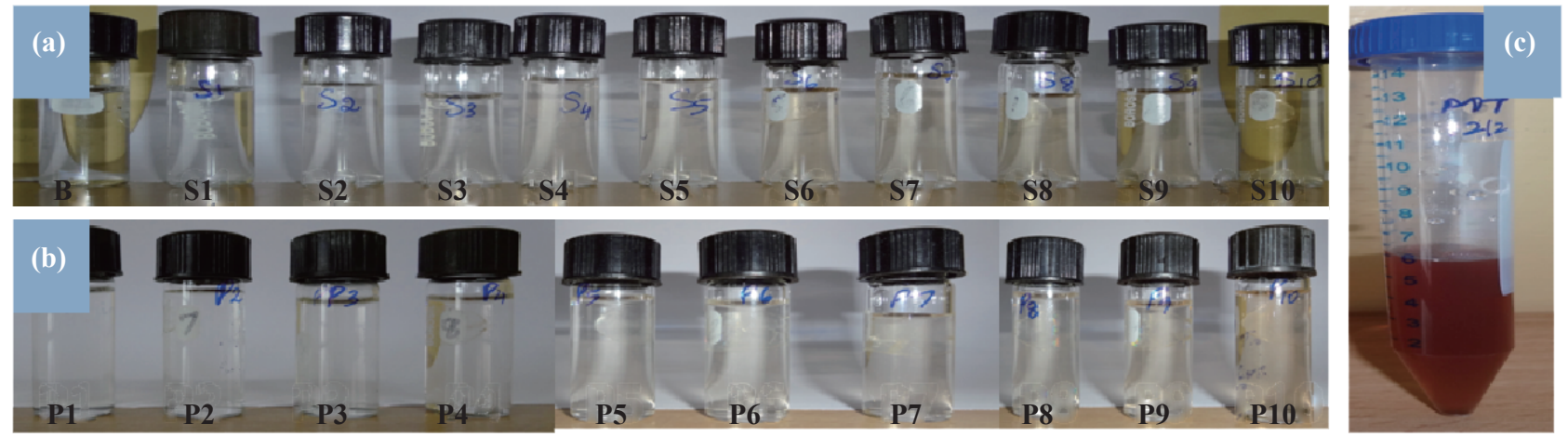

Fig. 1 The bottles containing silver nitrate solutions, plant extracts at different concentrations denoted as (a) S1-S10 and (b) P1-P10 respectively; (c) bottle containing purified, concentrated silver nanoparticles. 

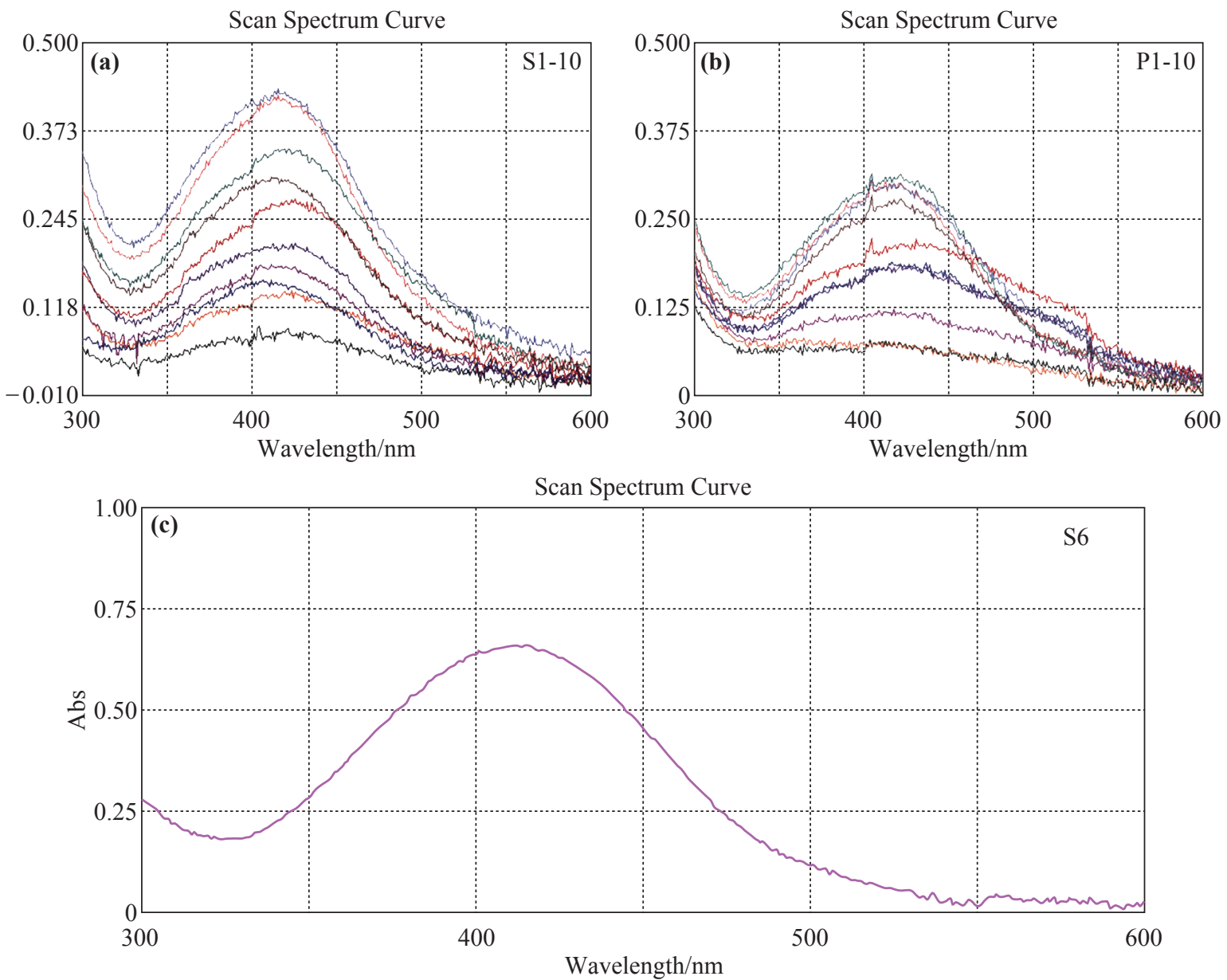

Fig. 2 (a) UV-visible spectrum of a mixture of solutions of silver nitrate S1-S10; (b) plant extracts P1-P10; (c) optimized silver nanoparticles synthesized using Mallotus tetracoccus leaves.

characteristic for surface plasmon resonance (SPR) of silver nanoparticles (Fig. 2(c)). Similar SPR of AgNPs synthesized by using seaweed Padina tetrastromatica showed an absorption peak at $424 \mathrm{~nm}$ (10). Here the biologically active molecules present in the leaf extract of MT have played a role in the reduction of silver nitrate to silver. The earlier investigations on the phytochemical constituents of Mallotus tetracoccus leaves revealed the presences of sugars, tannins, alkaloids, flavonoids, steroids, terpenoids and phenolic acids.

\section{Optimization of physicochemical parameters for synthesis of silver nanoparticles}

The formation of silver nanoparticles was optimized using different parameters: $\mathrm{pH}$ and temperature. $\mathrm{PH}$ and temperature play a very significant role in the synthesis of silver nanoparticles by controlling their shapes and sizes. The reaction medium was checked at different $\mathrm{pH}$ values for the production of optimized silver nanoparticles. PH 7 was said to give small, highly dispersed silver nanoparticles as indicated by their absorbance peaks at the nanometer scale, which was confirmed by the UV-Vis spectrum readings (Fig. $3)$. Among the different temperatures checked, the optimal production was observed at $60{ }^{\circ} \mathrm{C}$, where high temperature favoured the synthesis (Fig. 3). Similar green synthesis of AgNPs was reported at the temperature of $60{ }^{\circ} \mathrm{C}$ using leaf extracts of Tecomella undulata (11).

\section{Analysis of silver nanoparticles in AFM}

The surface morphology of AgNPs synthesized using leaf extract of MT was studied by AFM. The obtained morphology revealed the fact that the synthesized silver nanoparticles were almost spherical in shape, which was confirmed by the absorbance spectrum (Fig. 4). The sizes of the silver nanoparticles as observed by AFM were found to be in the range of 46 to $100 \mathrm{~nm}$, with an average size of $73 \mathrm{~nm}$. The particles were polydispersed and agglomerated due to the binding of some stabilising and capping agents 

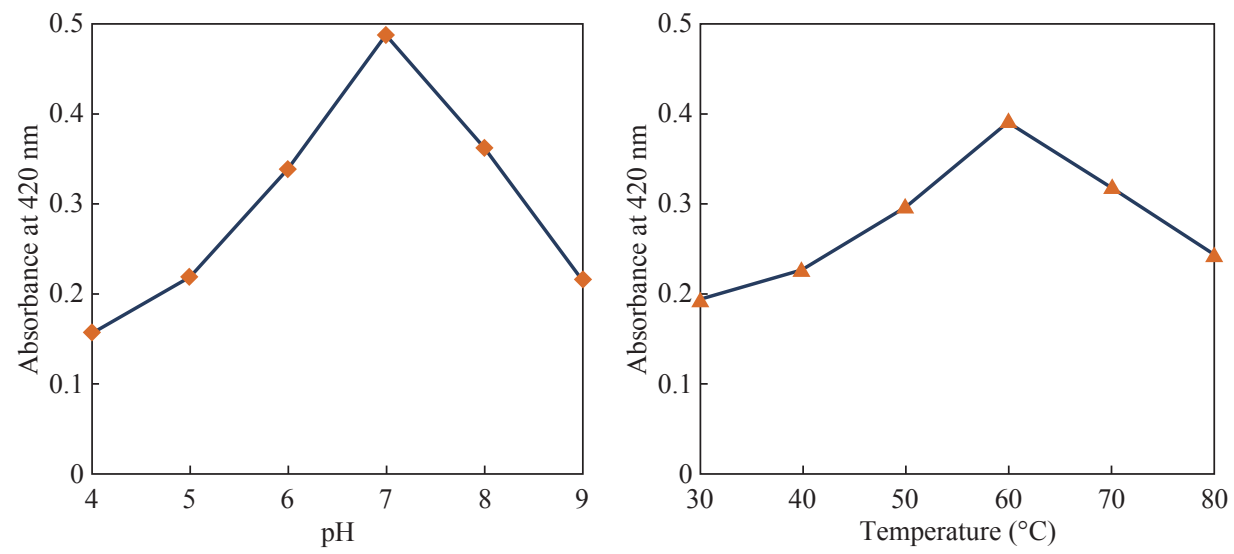

Fig. 3 Absorption spectrum for silver nanoparticles synthesized using Mallotus tetracoccus leaves at different $\mathrm{pH}$ values and temperatures.
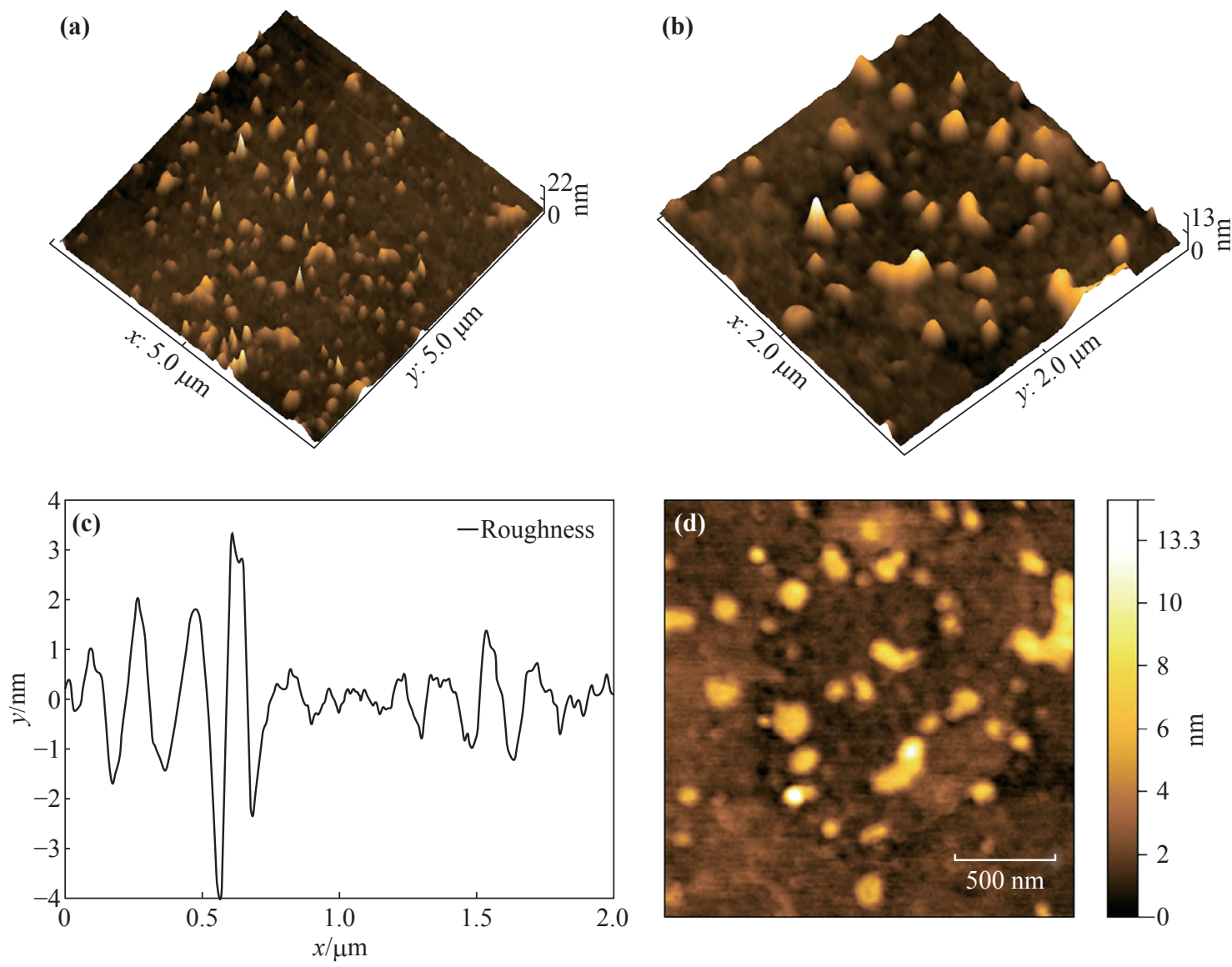

Fig. 4 AFM images obtained from the lyophilized sample of silver nanoparticles obtained from Mallotus tetracoccus, indicating the three dimensional images at the magnification of (a) $5 \mu \mathrm{m}$ and (b) $2 \mu \mathrm{m}$; (c) roughness data of nanoparticles at $2 \mu \mathrm{m}$; (d) two dimensional image of nanoparticles with sizes in the range of 46 to $100 \mathrm{~nm}$.

present in the MT extract. Figure 4 shows two and three dimensional views of the sample surface at the scan sizes of $2 \mu \mathrm{m} \times 2 \mu \mathrm{m}$ and $5 \mu \mathrm{m} \times 5 \mu \mathrm{m}$, depicting the agglomerated, polydispersed distribution of silver nanoparticles.

\section{Fourier transforms infrared spectroscopy (FTIR)}

FTIR analysis gives an idea of the functional groups involved in reduction of silver nitrate to nanosilver. The FTIR spectrum of the silver nanoparticle showed bands at 3425, 2922, 2854, 2368, 1593, 1018, 667 and $609 \mathrm{~cm}^{-1}$. Highly intense broad absorbance peak was observed at $3425 \mathrm{~cm}^{-1}$ characteristic of the $\mathrm{O}-\mathrm{H}$ stretching of phenolic compounds (Fig. 5). The bands at 2922, 2854 represents the C-H stretch (alkane H), 


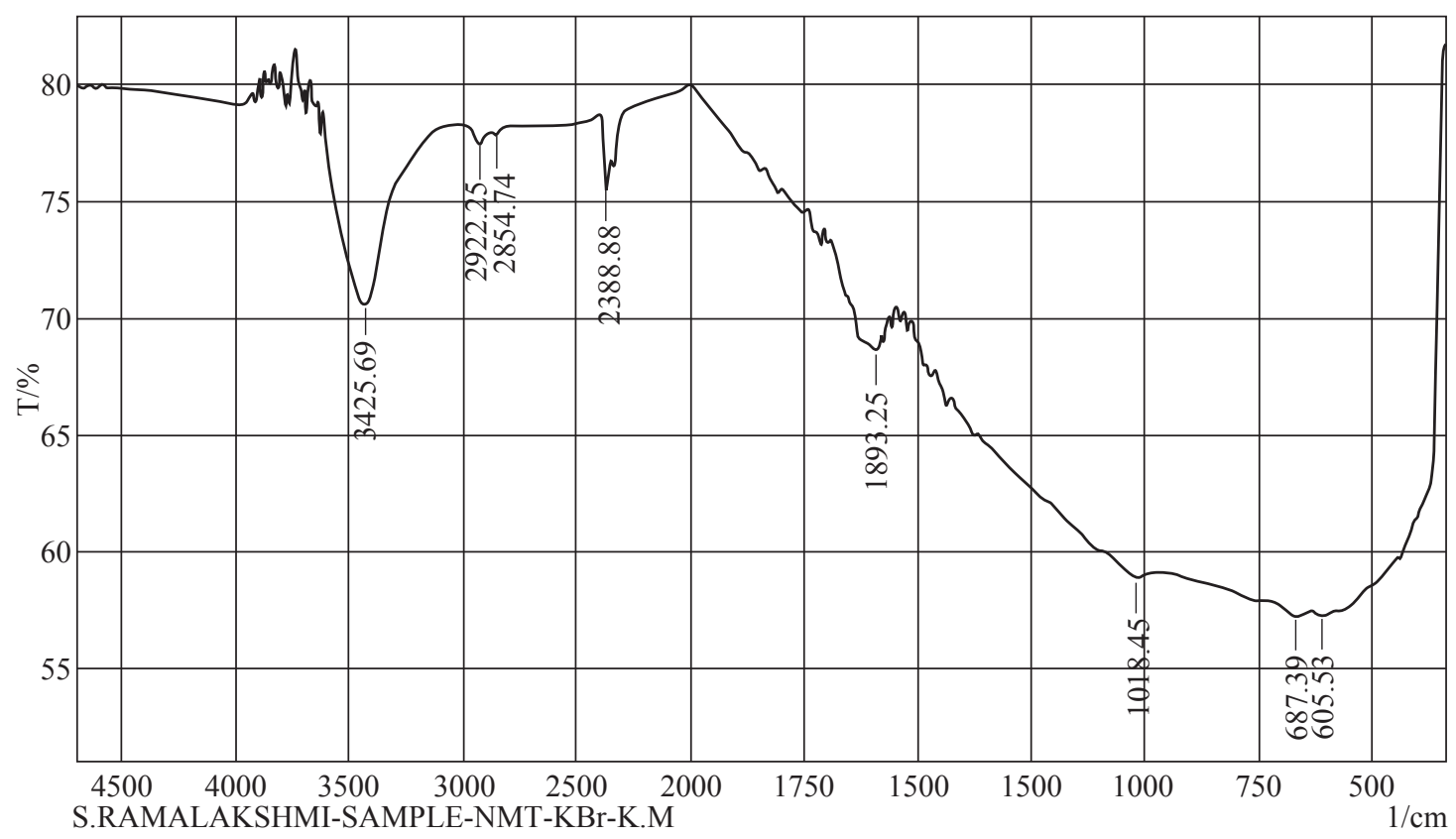

Fig. 5 FTIR spectrum for silver nanoparticles synthesized using Mallotus tetracoccus leaf extract.

$\mathrm{O}-\mathrm{H}$ stretching in carboxylic acids and bands at 2368 and 1593 corresponds to $\mathrm{C}=\mathrm{O}$ stretch in carboxylic acid respectively. Also the absorbance peak at 1018 $\mathrm{cm}^{-1}$ corresponds to the stretch vibration of $\mathrm{C}=\mathrm{C}$ and $\mathrm{C}-\mathrm{N}$ stretching vibrations of amine. Thus the silver nanoparticles are formed due to the interactions with the active compounds (secondary metabolites) of MT extract such as sugars, tannins, alkaloids, flavonoids, steroids, terpenoids and phenolic acids with silver nitrate to form nanoparticles. Thus the hydroxyl groups of phenols and carboxylic acids are involved in formation of AgNPs.

\section{SEM and EDX profiles}

SEM images were obtained from the lyophilised sample of silver nanoparticle synthesized from the leaf extract of MT (Fig. 6). Scanning electron microscope

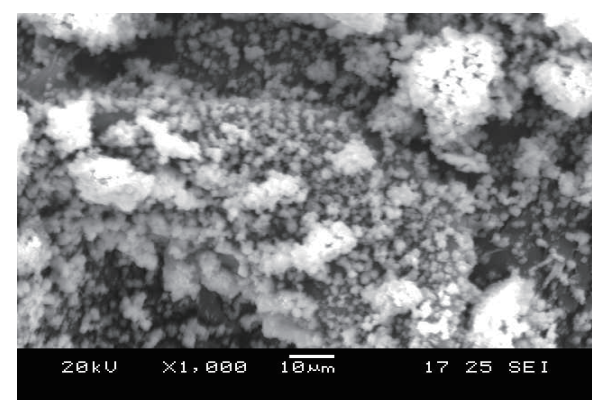

(a) images of the silver nano powder showed spherical morphology with agglomeration. The obtained size distribution was similar to that found in AFM. The energy dispersive X-ray spectroscopy profile for silver nanoparticles showed strong silver signal along with signals for $\mathrm{C}$ and $\mathrm{Mg}$, which may be due to the X-ray emission of the attached active molecules present on the surface of the silver nanoparticles (Fig. 7). Thus, the EDX reveals strong signal (78.38\%) in the silver region, confirming the formation of silver nanoparticles. Metallic silver nanocrystals generally show typical optical absorption peak approximately at $3 \mathrm{keV}$ due to surface plasmon resonance [12]. Various study reports on $\mathrm{AgNp}$ synthesized from plant extracts showed that several stabilizing agents act as capping agents and make the particles stable for a long time $[13,14]$.

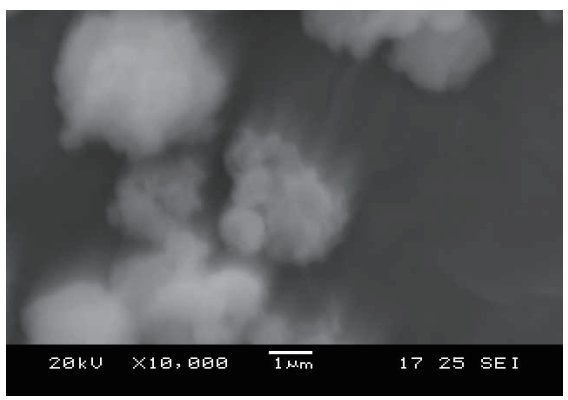

(b)

Fig. 6 SEM images of silver nanoparticles synthesized using Mallotus tetracoccus leaf extract at (a) $10 \mu \mathrm{m}$ and (b) $1 \mu \mathrm{m}$ magnifications. 


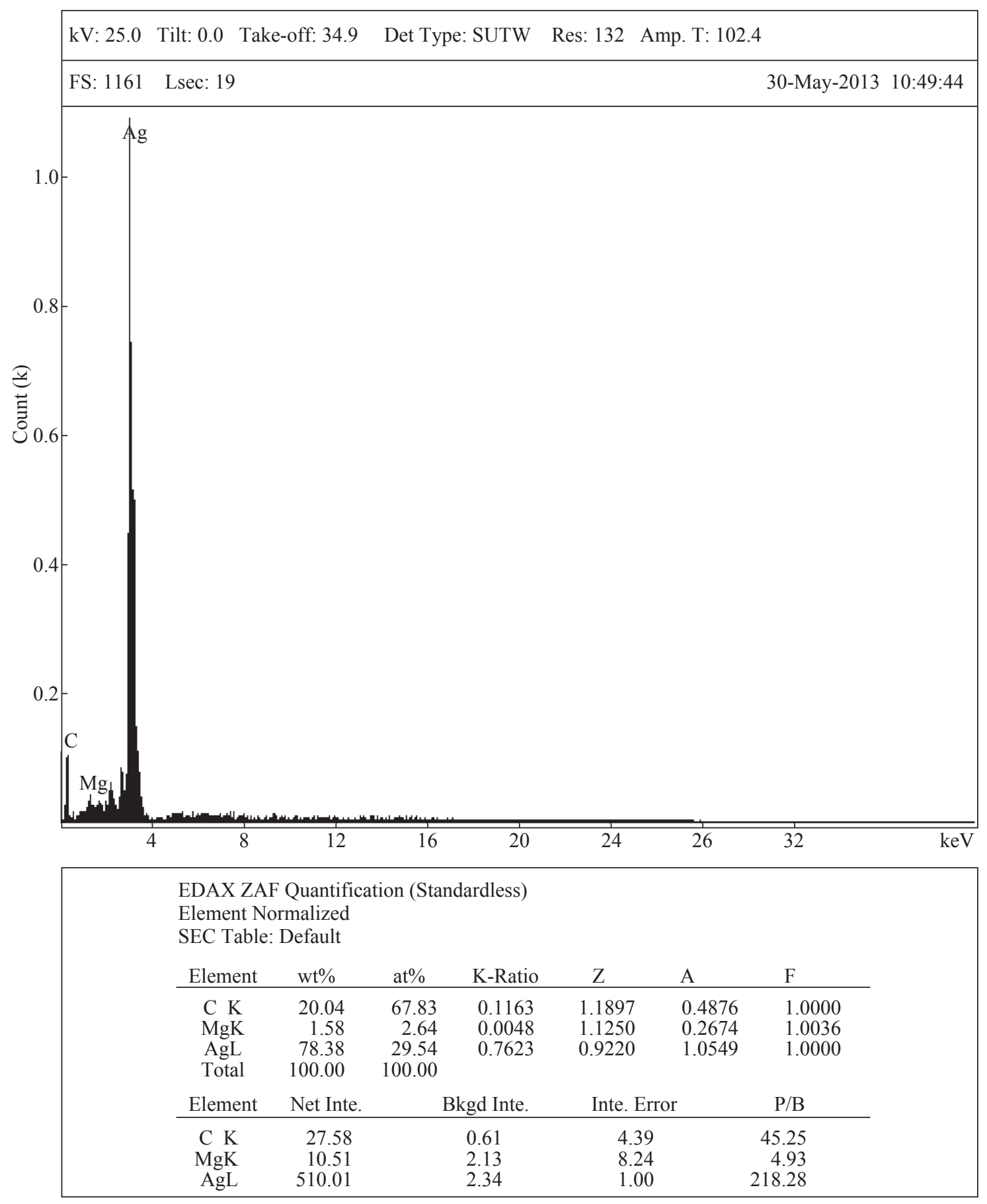

Fig. 7 EDX images of silver nanoparticles synthesized using Mallotus tetracoccus leaf extract.

\section{In vitro assessment of biosynthesized AgNPs cytotoxicity}

Today, assays based on cell culture play an important role in the screening of compounds for various anticancer studies. Thus, the results of cytotoxicity study on normal human fibroblast cells (L929) and human ductal breast carcinoma cells (T47D) are given as cytotoxicity percentage. NMT showed very less toxicity on normal cells $(4.4$ to $10.6 \%)$ at concentrations of 20 to $100 \mu \mathrm{g}$, whereas it exhibited highest cytotoxicity (76.8 to $84.9 \%$ ) on tumour cells (Fig. 8). Thus, the fact that AgNPs show higher cytotoxicity of $80-95 \%$ at concentrations of 20 to 100 $\mu \mathrm{g}$ represents its potential to effectively kill cancer cells.

Similar study results from earlier researchers also show that silver nanoparticles synthesized from plants can effectively kill cancer cells at lower concentrations 


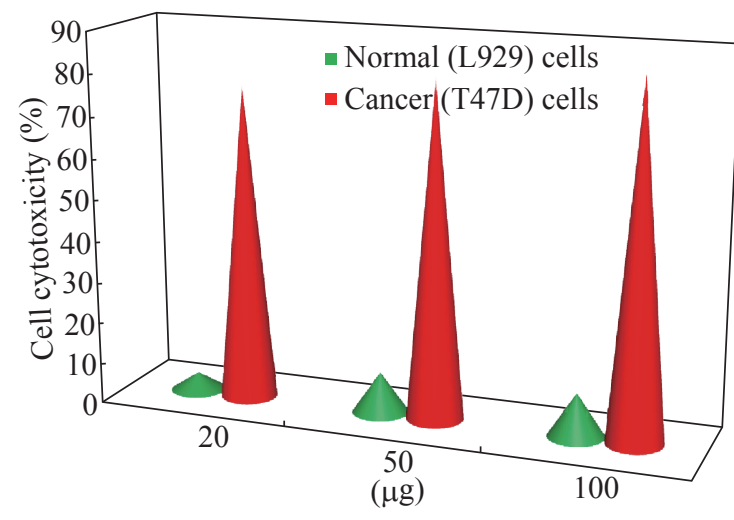

Fig. 8 MTT assay results confirm the in vitro cytotoxicity effect of AgNPs against the normal L929 cells and cancer T47D cells at 48 hrs.

[15]-[18]. The possible mode of the activity of silver nanoparticles on cancer cells has been reported by various researchers, that is, the created oxidative stress leads to depletion of GSH and induction of ROS, LPO, SOD and catalase in a dose dependent manner [16][18]. This stress causes interruption of ATP synthesis and mitochondrial damage, resulting in genotoxicity [22]. There is an interaction of AgNP with DNA, leading to cell cycle arrest in the G2/M phase [23]. There is also an increase in the activities of caspases, level of pro-inflammatory cytokines (interleukin$1 \mathrm{~b}$ (IL-1b) and interleukin-6 (IL-6)) in the treated cancer cells [21]. Reports also show that there is the involvement of mitochondria-dependent jun- $\mathrm{N}$ terminal kinase (JNK) pathway in AgNP toxicity [24]. Finally the cancer cells undergo apoptosis.

\section{Conclusions}

This study reports the green synthesis of silver nanoparticles using Mallotus tetracoccus leaf extract. The synthesis of silver nanoparticles was standardised at $\mathrm{pH} 7$ and the temperature of $60{ }^{\circ} \mathrm{C}$. The silver nanoparticles were characterized using AFM, FTIR and SEM with EDX. FTIR analysis of the nanoparticle sample indicates the involvement of hydroxyl and carboxyl functional groups of phenols in the reduction of silver nitrate to silver nanoparticles. The nanoparticles showed a spherical morphology with the size range of 49 to $98 \mathrm{~nm}$, and gave a strong silver signal in the EDX analysis. The AgNPs synthesized from MT leaf showed up to $85 \%$ cytotoxicity on cancer cells and very less toxicity on normal cells at the concentrations studied. Thus, further investigations are needed to prove its potential in in vivo studies for its application in cancer therapy.

\section{Acknowledgements}

The author Ramalakshmi Subbiah is thankful to University Grants Commission for providing meritorious fellowship (UGC-BSR) (Grant No. F.4$1 / 2006$ (BSR)/7-121/2007 (BSR)). The author is also thankful to USIC (University Science Instrumentation Centre), Dr. Suguna Shanmugasundram and Mr. K. Balachander, MKU for FTIR and AFM analysis.

\section{References}

[1] Y. Amakura, T. Yoshida, Tannins and related polyphenols of euphorbiaceous plants. 14. Euphorbin I, a new dimeric hydrolyzable tannin from Euphorbia watanabei. Chem. Pharm. Bull., 1996, 44: 1293-1297.

[2] X.F. Cheng, Z.L. Chen, Two new diterpenoids from Mallotus apelta Muell. Arg. J. Asian Nat. Prod. Res., 1999, 1: 319-325.

[3] D. Chattopadhyay, G. Arunachalam, A.B. Mandal, et al., Antimicrobial and anti-inflammatory activity of folklore: Mallotus peltatus leaf extract. J. Ethnopharmacol., 2002, 82: 229-237.

[4] H.S. Kim, H.K. Lim, M.W. Chung, et al., Antihepatotoxic activity of bergenin, the major constituent of Mallotus japonicus, on carbon tetrachloride-intoxicated hepatocytes. J. Ethnopharmacol., 2000, 69: 79-83.

[5] M. Arfan, H. Amin, M. Karamac, et al., Antioxidant activity of extracts of Mallotus philipensis fruits and bark. J. Food Lipids., 2007, 14: 280-297.

[6] S. Ramalakshmi, K. Muthuchelian, Anlaysis of bio-active constituents from the leaves of Mallotus tetracoccus (Roxb.) Kurz by gas chromatography-mass spectrometry. I. J. Pharma. Sci. Res., 2011, 2(6): 1449-1454.

[7] S. Ramalakshmi, K. Muthuchelian, Evaluation of antioxidant potential and antimicrobial studies of bark extract of medicinal plant, Mallotus tetracoccus (Roxb.) Kurz. J. Med. Plants. Res., 2012, 6(38): 5156-5165.

[8] S. Ramalakshmi, K. Muthuchelian, Studies on cytotoxic, phytotoxic and volatile profile of bark extract of important medicinal plant, Mallotus tetracoccus (Roxb.) Kurz. Afr. J. Biotech., 2013, 12(43): 6176-6184.

[9] S. Prabhu, E.K. Poulose, Silver nanoparticles: mechanism of antimicrobial action, synthesis, medical applications, and toxicity effects. I. Nano Letters, 2012, 2.

[10] K.F. Princy, S. Manomi, R. Philip, et al., Antibacterial and catalytic efficacy of biosynthesized silver nanoparticles using marine seaweed Padina tetrasromatica. Nano Biomed. Eng., 2016, 8(1): 16-23.

[11] S.K. Chaudhuri, S. Chandela and L. Malodia, Plant mediated green synthesis of silver nanoparticles using Tecomella undulata leaf extract and their characterization. Nano Biomed. Eng., 2016, 8(1): 1-8.

[12] P. Magudapathi, P. Gangopadhyay, E.K. Panigrahi, et al., Electrical transport studies of silver nanoparticles embedded in glass matrix. Physica B., 2001, 299: 142146.

[13] J.Y. Song, B.S. Kim. Rapid biological synthesis of silver nanoparticles using plant leaf extracts. Bioprocess. Biosyst.Eng., 2009, 32: 79-84.

[14] M. Singh, R.C. Kalaivani, M. Anand, et al., Rapid biomimetic synthesis of silver nanoparticles from Asiatic mangrove (Rhizopora mucronata) and its antimicrobial activity against clinically isolated pathogens. Proceedings of the International Conference on Nanoscience, 
Engineering and Technology (ICONSET 2011). Kalpakkam, India, Nov. 28-30, 2011.

[15] R. Vivek, R. Thangam, K. Muthuchelian, et al., Green biosynthesis of silver nanoparticles from Annona squamosa leaf extract and its in vitro cytotoxic effect on MCF-7 cells. Process Biochem., 2012, 47: 2405-2410.

[16] K. Renugadevi, D. Inbakandan, M. Bavanilatha, et al., Cissus quadrangularis assisted biosynthesis of silver nanoparticles with antimicrobial and anticancer potentials. Int. J. Pharm. Bio. Sci., 2012, 3: 437-445.

[17] S. Das, J. Das, A. Samadder, et al., Biosynthesized silver nanoparticles by ethanolic extracts of Phytolacca decandra, Gelsemium sempervirens, Hydrastis canadensis and Thuja occidentalis induce differential cytotoxicity through G2/M arrest in A375 cells. Colloids Surf B.: Biointerf., 2013, 101: 325-336.

[18] K. Khanra, S. Panja, I. Choudhuri, et al., Bactericidal and cytotoxic properties of silver nanoparticle synthesized from root extract of Asparagus racemosus. Nano Biomed. Eng., 2016, 8(1): 39-46.

[19] S. Gurunathan, J.W. Hana, A.A. Dayem, et al., Green synthesis of anisotropic silver nanoparticles and its potential cytotoxicity in human breast cancer cells (MCF7). J. Ind. Eng. Chem., 2013, 19: 1600-1605.

[20] M. Jeyaraj, M. Rajesh, R. Arun, et al., An investigation on the cytotoxicity and caspase-mediated apoptotic effect of biologically synthesized silver nanoparticles using Podophyllum hexandrum on human cervical carcinoma cells. Colloids Surf B., 2013, 102: 708-717.

[21] A.O. Suliman, D. Ali, S. Alarifi, et al., Evaluation of cytotoxic, oxidative stress, proinflammatory and genotoxic effect of silver nanoparticles in human lung epithelial cells. Environ. Toxicol., 2013. DOI: 10.1002/ tox. 21880 .

[22] R. Foldbjerg, D.A. Dang and H. Autrup, Cytotoxicity and genotoxicity of silver nanoparticles in the human lung cancer cell line, A549. Arch. Toxicol., 2011, 85: 743-750.

[23] P.V. Asharani, G.L.K. Mun, M.P. Hande, et al., Cytotoxicity and genotoxicity of silver nanoparticles in human cells. ACS Nano, 2009, 3: 279-290.

[24] Y.H. Hsin, C.F. Chen, S. Huang, et al., The apoptotic effect of nanosilver is mediated by a ROS- and JNKdependent mechanism involving the mitochondrial pathway in nih3t3 cells. Toxicol. Lett., 2008, 179: 130139.

Copyright $\odot 2016$ Ramalakshmi Subbiah, Krishnaswamy Muthuchelian. This is an open-access article distributed under the terms of the Creative Commons Attribution License, which permits unrestricted use, distribution, and reproduction in any medium, provided the original author and source are credited. 